\title{
The 'clip-band closure' technique: a new endoscopic traction method for closure of a large ulcer
}
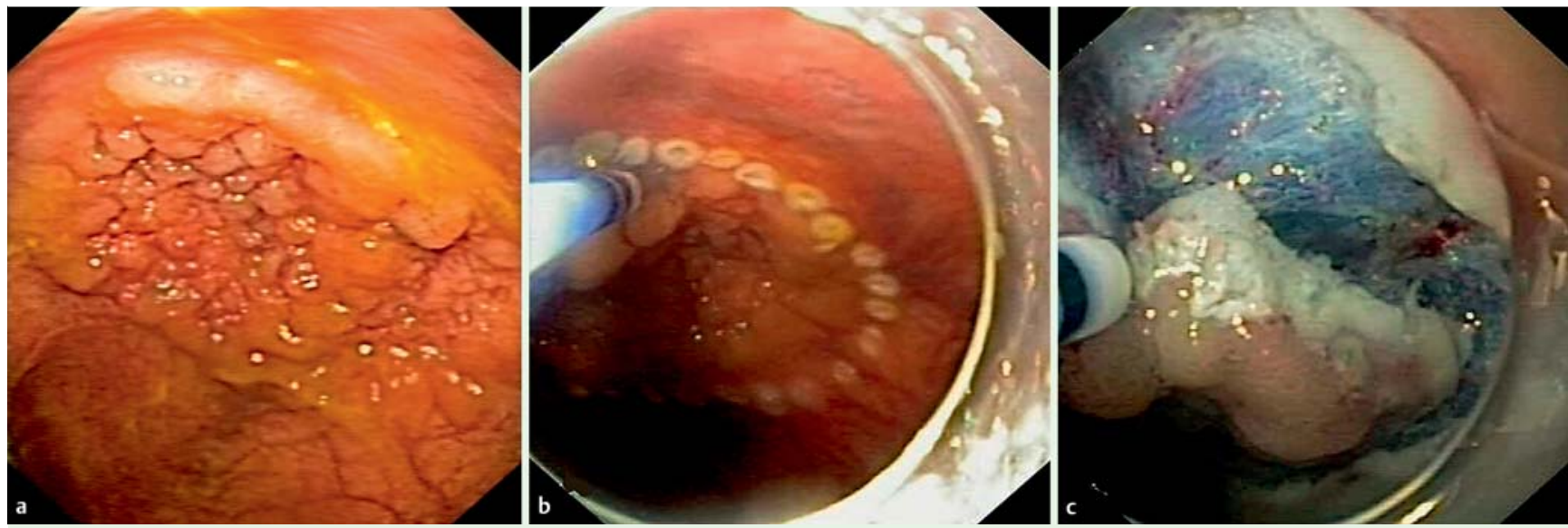

Fig. 1 Endoscopic views of a rectal laterally spreading tumor (LST) in a 69-year-old man: a before endoscopic submucosal dissection (ESD); b, c during ESD.
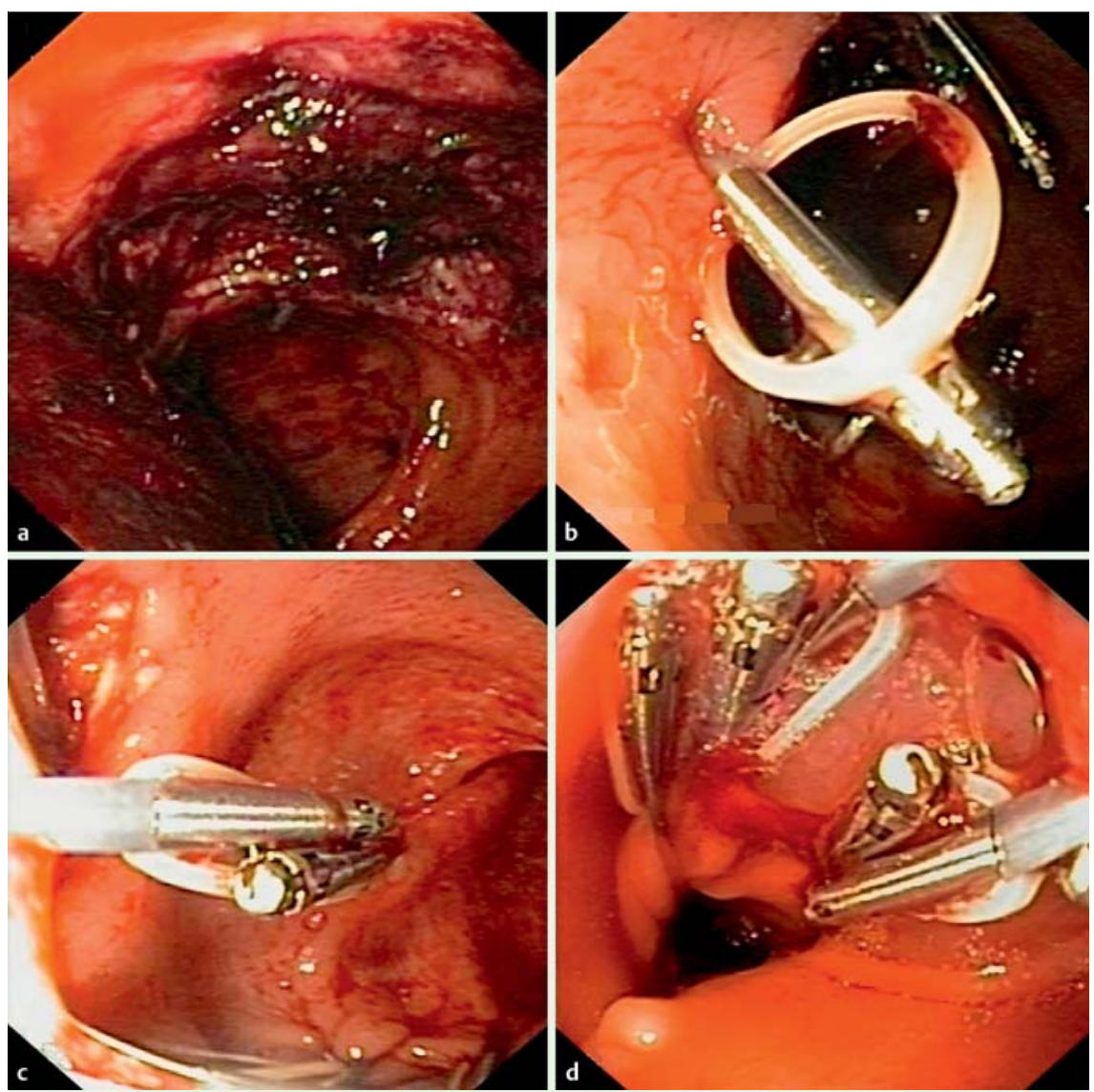

Fig. 2 Endoscopic views during the clip-band closure technique showing: a the appearance of the ulcer following endoscopic submucosal dissection (ESD) soon after bleeding was noted; $\mathbf{b}$ the clip with the loaded band attached to the proximal ulcer margin; $\mathbf{c}$ the clip-band after traction attached to the mucosa distal to the ulcer; $\mathbf{d}$ the completed clip-band closure.

We present the case of a 69-year-old man with a rectal granular-type laterally spreading tumor (LST) of about $50 \mathrm{~mm}$ in diameter who underwent endoscopic submucosal dissection (ESD) using a Hybrid knife I-type (Erbe, Tübingen, Germany) at our institute ( $\bullet$ Fig. $\mathbf{1})$.

The following day, the patient developed rectal bleeding, and endoscopy revealed a large post-ESD ulcer with clots at the base $(\bullet$ Fig.2a). After rinsing the clots, we decided to attempt closure of the ulcer using a new technique, which we called the 'clip-band closure' technique.

First, a rubber band used for orthodontic treatment $(5-6 \mathrm{~mm}$ in diameter and 56.7-99.2g in strength; ORMCO Corp., Glendora, California, USA) was preloaded onto the open prongs of a Resolution clip (Boston Scientific, Natick, Massachusetts, USA). The clip with the loaded band was inserted through the working channel of the endoscope and attached to the proximal inner margin of the ulcer ( $\boldsymbol{~ F i g . 2} \mathbf{b}$ ). The band was then clamped again with a second clip, which was pushed towards the opposite mucosal edge distal to the ulcer where it was attached ( $\bullet$ Fig. 2 c). The same clip/band sequence was applied at two other points on the ulcer edge to further draw the ulcer margins together ( $\bullet$ Fig. 2d).

No more episodes of bleeding were recorded in the following days and 1 week later a follow-up endoscopy confirmed closure of the ulcer, with the clips and 


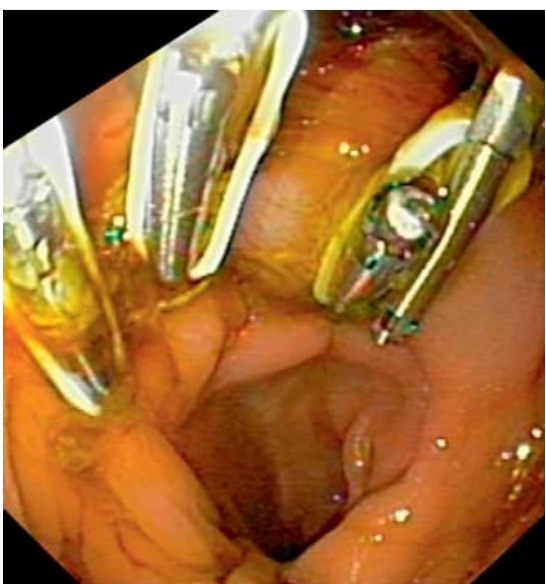

Fig. 3 Endoscopic view 1 week after the clipband closure technique had been performed.

band still in the correct positions (๑ Fig. 3).

Although endoclips may help in the closure of small mucosal defects, a variety of different endoscopic techniques have been described for the treatment of larger defects [1-3]. Parra-Blanco et al. described the clip-band technique to improve visualization of the submucosal layer during ESD [4]. In this report, we applied a similar clip-band sequence to close a large post-ESD ulcer. This technique appears feasible and safe, and may represent a useful new endoscopic closure technique.

Endoscopy_UCTN_Code_TTT_1AQ_2AD

Competing interests: None

G. Curcio' ${ }^{1}$ A. Granata' , N. Azzopardi', D. Pagano², L. Barresi', I. Tarantino', M. Spada ${ }^{2}$, M. Traina ${ }^{1}$

${ }^{1}$ Gastroenterology and Endoscopy Unit, Mediterranean Institute for Transplantation and Advanced Specialized Therapies (ISMETT), Palermo, Italy

2 Department of Surgery, Mediterranean Institute for Transplantation and Advanced Specialized Therapies (ISMETT), Palermo, Italy

\section{References}

1 Banerjee S, Barth BA. ASGE Technology Committee et al. Endoscopic closure devices. Gastrointest Endosc 2012; 76: 244 - 251

2 Mocciaro F, Curcio G, Tarantino I et al. Tulip bundle technique and fibrin glue injection: unusual treatment of colonic perforation. World J Gastroenterol 2011; 17: 1088 - 1090
3 Curcio G, Traina M, Panarello G et al. Refractory gastric ulcer bleeding treated with new endoloop/clips technique. Dig Endosc 2011; 23: $203-204$

4 Parra-Blanco A, Nicolas D, Arnau MR et al. Gastric endoscopic submucosal dissection assisted by a new traction method: the clip-band technique. A feasibility study in a porcine model (with video). Gastrointest Endosc 2011; 74: 1137-1141

\section{Bibliography}

Dol http://dx.doi.org/

10.1055/s-0032-1326499

Endoscopy 2013; 45: E171-E172

(C) Georg Thieme Verlag KG

Stuttgart · New York

ISSN 0013-726X

\section{Corresponding author}

G. Curcio, MD

Gastroenterology and Endoscopy Unit Mediterranean Institute for Transplantation and Advanced Specialized Therapies (ISMETT) Via Tricomi, 1

Palermo 90100

Italy

Fax: +39-091-2192400

gcurcio@ismett.edu 